\title{
Numerical Simulation and Preparation of Cladding Billet by Direct Chill Semi-Continuous Casting
}

\author{
Han Xing, Zhang Haitao*, Shao Bo, Zuo Kesheng, He Lizi, Qin Ke and Cui Jianzhong \\ Key Laboratory of Electromagnetic Processing of Materials, Ministry of Education, Northeastern University, \\ Shenyang 110819, China
}

\begin{abstract}
This study presents an innovative direct chill semi-continuous casting process to prepare AA4045/AA3003 cladding billet using numerical simulation and experiments. The influence of casting speed on temperature field in cladding billet has been investigated by the commercial software FLUENT and validated by experiments. The cladding billet was examined by methods of metallographic examination, field emission scanning electron microscopy (FESM) and universal testing machine. The results show that the experiments are in good agreement with the simulation results. Cladding billets can be obtained at the casting speeds ranging from $110 \mathrm{~mm} / \mathrm{min}$ to $150 \mathrm{~mm} / \mathrm{min}$. Excellent metallurgical bonding of the two alloys could be achieved at the casting speed of $130 \mathrm{~mm} / \mathrm{min}$ and $150 \mathrm{~mm} / \mathrm{min}$. With the increase of casting speed, increasing contact temperature promotes the interdiffusion of alloy elements. The tensile strength and shear strength of interface reaches $106 \mathrm{MPa}$ and $77 \mathrm{MPa}$ respectively. Moreover, fracture position moves to AA3003 side from the interface in tensile test, while fracture mode changes to the ductile from the brittle as casting speed increases. [doi:10.2320/matertrans.M2015229]
\end{abstract}

(Received June 5, 2015; Accepted August 27, 2015; Published October 25, 2015)

Keywords: cladding billet, casting speed, contact temperature, diffusion, interfacial strength

\section{Introduction}

As the existing and potential industrial applications, multilayer materials laminate or cladding tubular products is playing a more and more significant role in modern industries because of their advantages, such as excellently physical, chemical and mechanical performance that conventional monolithic materials do not have. ${ }^{1-4)}$ Tubular products or sheets could be extensively used to make corrosion resistant aluminum products, radiator, heat exchangers, condenser pipes, and so on. ${ }^{5)}$ In the past decades, a series of processes used for preparation of cladding materials had been developed, involving rolling bonding, ${ }^{6,7)}$ explosive welding, ${ }^{8,9)}$ diffusion bonding, ${ }^{10)}$ extrusion cladding, ${ }^{11,12)}$ spray deposition technique ${ }^{13)}$ et al. However, the adherence issue of the mating surface between the clad and core layers could not be resolved properly, thus limiting the strength of the laminated billets. To overcome such a challenge, Novelis has recently developed the Fushion ${ }^{\mathrm{TM}}$ Technology process that allows simultaneously direct-chill casting single or double alloy layers into a single aluminum rolling billet for manufacturing various types of multiple alloy or clad sheets products. ${ }^{14)}$ E.I. Marukovich et al. ${ }^{15)}$ studied the possibility experimentally and numerically for producing bimetallic components by mean of horizontal continuous-casting in condition of direct connection of metals in a liquid state. AMIR R. Baserinia et al. ${ }^{16)}$ developed a numerical steadystate thermofluids model for the FusionTM technology casting process to simulate the casting of rectangular bimetallic billets and conducted to cast AA3003/AA4045 clad ingots via FusionTM Technology. Fu et al. ${ }^{17)}$ prepared Al-1Mn and Al10Si alloys circular clad ingot by direct chill semi-continuous casting. However, in some particular conditions, bimetal materials are required to be tubular or wirelike and satisfy the strict standard of the clad ratio. ${ }^{18)}$ Most processes mentioned above focused on how to achieve composite ingot. Neither the

*Corresponding author, E-mail: haitao_zhang@epm.neu.edu.cn investigations of cladding billet with a low clad ratio, nor the effect of process parameters on cladding billet, has been reported because of the requirement of more complex crystallizer system and advanced casting technology.

In this paper, the casting process of cladding billets was investigated by numerical simulation and experiments. The influence of casting speed on the formability and bonding of the two alloys was discussed in detail.

\section{Methodology}

\subsection{Mathematical model of the cladding casting process}

To investigate the influence of casting parameters on the cladding billet, a mathematical model is used to describe the cladding casting process.

In this study, a single domain volume-average model is applied to the clad and core materials. Single region models are built on governing equations that apply to all regions of solidification system. The model equations can be integrated across the entire domain without the need to explicitly subdivide the domain into solid, liquid and mushy regions. ${ }^{19)}$ Instead, these regions are implicitly defined within the system by distributions of energy determined from the solutions model equations. The flow field of melts is described by conservation equation of mass and conservation equation of momentum, and temperature fields are described by the conservation equation of energy. In this model, the fluid flow, heat transfer and solidification are coupled so that the interaction of the multi-physics field during the process could be described accurately. The interface of the two alloys is treated as stationary wall relatively, and the heat transfer of them is coupled.

In order to simplify the question, some assumptions are given as follow:

(1) The calculation about the solute field is not included in the research;

(2) The interaction between two kinds of melts is negligible; 
Table 1 Governing equations used in the model.

\begin{tabular}{cc}
\hline Governing equations' name & Modified governing equation \\
\hline $\begin{array}{c}\text { Conservation equation of mass } \\
\text { Conservation equation of momentum } \\
\text { Conservation equation of energy }\end{array}$ & $\nabla \cdot(\rho U U)=\nabla \cdot\left(\mu_{\mathrm{eff}} \nabla U\right)-\nabla P+S_{\mathrm{m}}$ \\
$\begin{array}{c}\text { Conservation equation of turbulence kinetic energy } \\
\text { Conservation equation of dissipation rate of } \\
\text { turbulence kinetic energy }\end{array}$ & $\nabla \cdot(\rho U T)=\nabla \cdot\left(\frac{k}{C_{\mathrm{p}}} \nabla T\right)+S_{\mathrm{th}}$ \\
\hline
\end{tabular}

(3) The melts in the mold are taken as homogeneous medium;

(4) Aluminum alloy is deemed to be incompressible fluid, namely its density is a constant. But the thermal buoyancy must be included in this model; therefore the Boussinesq approximation is used to calculate the thermal buoyancy and is expressed as:

$$
F_{\text {thermal }}=\rho_{1} \beta\left(T-T_{0}\right)
$$

Where $\rho_{1}$ and $\beta$ are the density and the volume expansion coefficient of the molten aluminum, respectively, $T_{0}$ is the reference temperature and is frequently given as the temperature of the solid fraction of dendrite contact.

In AA4045/AA3003 cladding billet of cladding casting process, the solidified part moves along the axial with casting speed.

According to above assumptions, the governing equations used in the mathematic model are modified as shown in Table 1 . In these equations, $\mu_{\mathrm{eff}}$ and $S_{\mathrm{m}}$ are effective viscosity and momentum source, respectively. The effective viscosity $\mu_{\text {eff }}$ is given by $\mu_{\text {eff }}=\mu_{1}+\mu_{\mathrm{t}}$, where $\mu_{1}$ is laminar viscosity in the liquid and $\mu_{\mathrm{t}}$ is turbulent viscosity. The momentum source $S_{\mathrm{m}}$ includes thermal buoyancy and Darcy source term. In the eq. (4), $S_{\text {th }}$ is thermal source, i.e., latent heat of solidification. $K, x$ are permeability and very small positive number to avoid diverging of conversation equations. Permeability $K$ is given as a function of solid fraction $f_{\mathrm{s}}$, i.e., $K=K_{0}\left(1-f_{\mathrm{s}}\right)^{3} / f_{\mathrm{s}}$. $G_{\mathrm{k}}$ represents the generation of turbulence kinetic energy due to the mean velocity gradients, calculated as follows: $G_{k}=-\overline{\rho \mu^{\prime} \mu_{j}^{\prime}}\left(\vartheta \mu_{j} / \vartheta x_{i}\right)$. C1 and C2 are constants. $\sigma_{k}$ and $\sigma_{\varepsilon}$ are the turbulent Prandtl number for $k$ and $\varepsilon$, respectively.

In addition, the lower Reynold numbers model is applied because it has relatively low mesh requirements and is widely used and verified in various numerical engineering applications. A one-half symmetry model is used to reduce the calculation amount. The mesh model and boundaries are shown in Fig. 1. From the former work, ${ }^{20)}$ the boundary conditions are set in detail. The thermophysical properties and other material properties of the alloys used during the calculation procedure are listed in Table 2.

\subsection{Materials and experiments}

As commonly used commercial alloys, AA4045 has remarkable weldability, while AA3003 has excellent corrosion resistance. Their components are list in Table 3. The condenser pipe prepared by the two aluminum alloys could combine their advantages and be available to the automotive heat exchangers for automobile lightening. ${ }^{21)}$ (a)

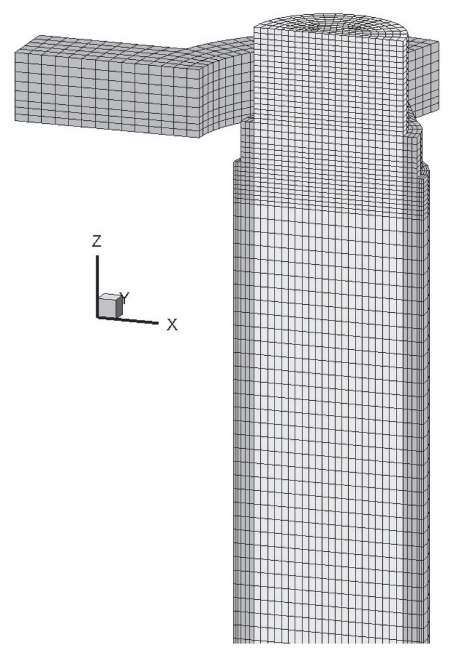

(b)

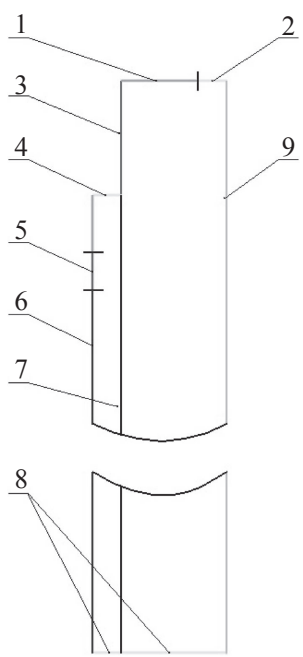

Fig. 1 The computational mesh model (a) and boundary conditions (b): 1 free surface; 2 inlet-AA3003; 3 inner mold; 4 inlet-AA4045; 5 outer mold; 6 second cooling; 7 interface; 8 outlet; 9 symmetry axis.

Table 2 Physical properties and constants used in the numerical simulation.

\begin{tabular}{ccc}
\hline Physical property & $\begin{array}{c}3003 \text { aluminum } \\
\text { alloy }\end{array}$ & $\begin{array}{c}4045 \text { aluminum } \\
\text { alloy }\end{array}$ \\
\hline Density, $\rho /\left(\mathrm{Kg} / \mathrm{m}^{3}\right)$ & 2520 & 2420 \\
Liquidus, $t_{\mathrm{l}} / / \mathrm{K}$ & 658 & 596 \\
Solidus, $t_{\mathrm{s}} / \mathrm{K}$ & 645 & 577 \\
Latent heat of crystallize, $S_{\mathrm{th}} /\left(\mathrm{JKg}^{-1}\right)$ & $3.9 \times 105$ & $4.7 \times 105$ \\
Coefficient of cubic expansion, $\beta / \mathrm{K}^{-1}$ & $6.7 \times 10-5$ & $5.2 \times 10-5$ \\
Original permeability, $k_{\mathrm{p}}$ & $2 \times 10-11$ & $2 \times 10-11$ \\
Solid fraction of dendrite contact, $f^{*}$ & 0.3 & 0.25 \\
Reference temperature, $t_{\mathrm{ref}} /{ }^{\circ} \mathrm{C}$ & 652 & 569 \\
\hline
\end{tabular}

Table 3 Alloy compositions.

\begin{tabular}{ccccccccc}
\hline Elements & $\mathrm{Si}$ & $\mathrm{Fe}$ & $\mathrm{Cu}$ & $\mathrm{Mn}$ & $\mathrm{Mg}$ & $\mathrm{Zn}$ & $\mathrm{Ti}$ & $\mathrm{Al}$ \\
\hline $\begin{array}{c}\text { mass\% } \\
\text { (AA3003) }\end{array}$ & 0.6 & 0.7 & $0.05 \sim 0.20$ & $1.0 \sim 1.5$ & - & 0.10 & - & Balanced \\
$\begin{array}{c}\text { mass\% } \\
\text { (AA4045) }\end{array}$ & $9 \sim 11$ & 0.8 & 0.30 & 0.05 & 0.05 & 0.10 & 0.20 & Balanced \\
\hline
\end{tabular}

The apparatus of semi-continuous casting for fabricating cladding billets were designed and schematically shown in Fig. 2. It mainly contains inner-crystallizer, outer-crystallizer, their respective pouring system and cooling system. During the casting process, AA3003 was poured into the inner- 


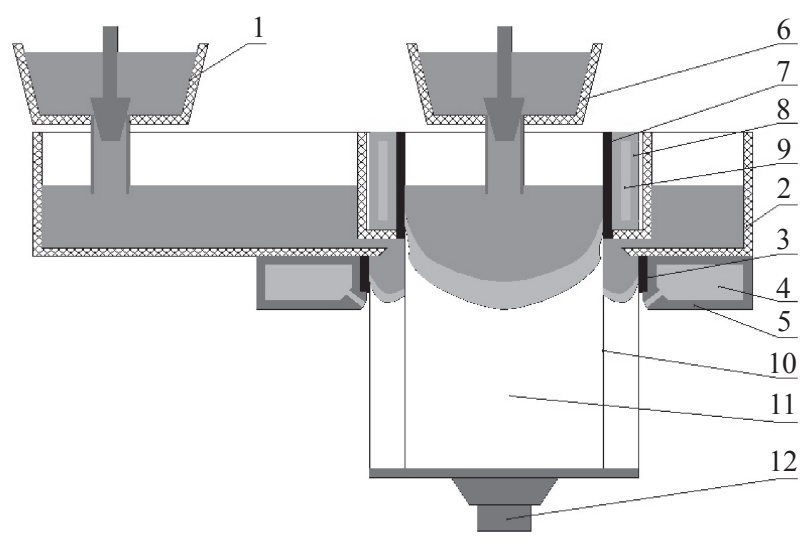

Fig. 2 Schematic diagrams of cladding casting equipment: outer-crystallizer, 1 clad tundish, 2 launder, 3 outer-graphite, 4 cooling water, 5 outermold; inner-crystallizer, 6 core tundish, 7 inner-graphite, 8 inner-mold, 9 cooling water; 10 bonding interface; 11 cladding billet; 12 starting head.
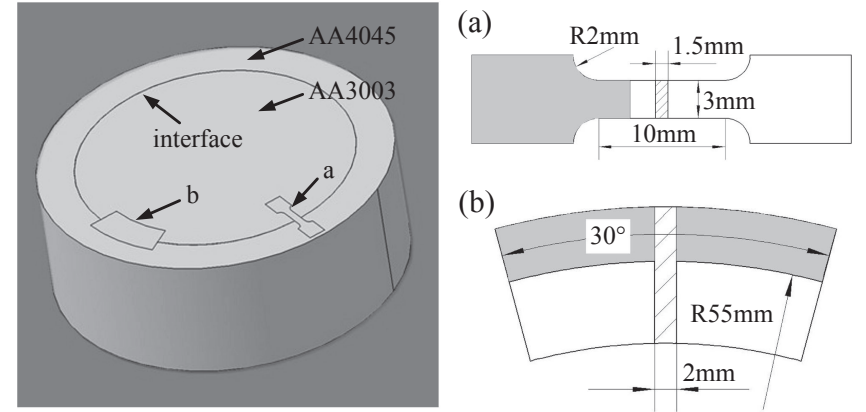

(b)

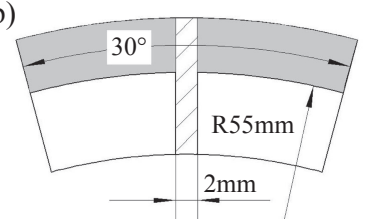

Fig. 3 Schematic illustration of sampling location of tensile (a) and shear (b) specimens. (a)

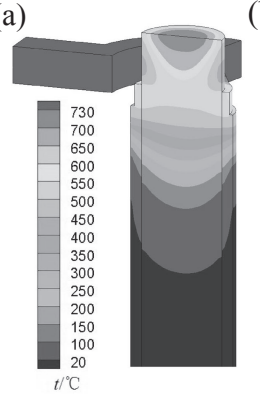

(b)

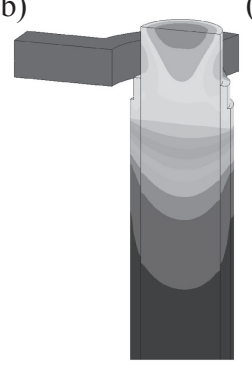

(c) (d) (e)

Fig. 4 3D-surface plot of temperature contours under different casting speed: (a) $v=90 \mathrm{~mm} / \mathrm{min}$; (b) $v=110 \mathrm{~mm} / \mathrm{min}$; (c) $v=130$ $\mathrm{mm} / \mathrm{min}$; (d) $v=150 \mathrm{~mm} / \mathrm{min}$; (e) $v=170 \mathrm{~mm} / \mathrm{min}$.

crystallizer firstly. Under the cooling of the inner-mold, a supporting layer would form at the inner-graphite in several seconds. When the strength of the supporting layer was sufficient to prop up the internal liquid metal and the surface of the supporting layer remained at relatively high temperature, AA4045 was poured into the outer-crystallizer rapidly and flowed into the outer-crystallizer, and the starting head was drown at the same time. Then, the casting of cladding billets began when AA4045 melt contacted with the supporting layer of AA3003. Finally, the cladding billet in size of $\Phi 140 \mathrm{~mm} / \Phi 110 \mathrm{~mm}$ was prepared successfully.

In authors' former work, a comprehensive mathematical model had been developed to describe the variation and the interaction of the multiple physics fields during the cladding casting process. The model has been verified by experiments. ${ }^{20)}$ The present study aimed to investigate the influence of casting speed on temperature field, the formability and bonding of the two alloys. Basing on the simulation results, the casting speed takes several different values, remaining other technical parameters constants as list in Table 4.

The as-cast samples were polished and etched using a solution of $10 \% \mathrm{NaOH}$ (in mass) to observe the macrostructure, another solution of 5\% HF (in volume) to examine the microstructure by metalloscope (Leica DMR), respectively. The distribution of the $\mathrm{Si}$ and $\mathrm{Mn}$ elements across the interface at different casting speed was analyzed by scanning electron microscope (Zeiss Ultra Plus 60). In order to evaluate the interfacial strength of different cladding billets,
Table 4 Casting process parameters during the cladding casting.

\begin{tabular}{cccc}
\hline alloys & $\begin{array}{c}\text { Casting temperature } \\
/{ }^{\circ} \mathrm{C}\end{array}$ & $\begin{array}{c}\text { Casting speed } \\
/ \mathrm{mm} \cdot \mathrm{min}^{-1}\end{array}$ & $\begin{array}{c}\text { Cooling water flow rate } \\
/ \mathrm{L} \cdot \mathrm{min}^{-1}\end{array}$ \\
\hline AA3003 & 720 & $90-170$ & 30 \\
AA4045 & 730 & $90-170$ & 60 \\
\hline
\end{tabular}

the tensile test and the shear test were performed by MTS810 universal testing machine.

Samples to investigate mechanical properties were cut across the interface as the similar position, tensile specimen (a) and shear specimen (b) in Fig. 3.

\section{Results and Discussion}

\subsection{Simulation results of cladding casting}

Based on the above simulation model and basic assumptions, the temperature profiles during the stable period of direct chill semi-continuous casting were obtained with casting speed, $90 \mathrm{~mm} / \mathrm{min}, 110 \mathrm{~mm} / \mathrm{min}, 130 \mathrm{~mm} / \mathrm{min}, 150$ $\mathrm{mm} / \mathrm{min}$ and $170 \mathrm{~mm} / \mathrm{min}$, respectively, as shown in Fig. 4. It can be known that AA3003 melt close to the inner-mold was cooled, formed gradually a supporting layer and reheated by AA4045 melt poured into the outer-mold. As casting, the cladding billet was cooled to room temperature. Moreover, with the increase of casting speed, the temperature (called 
(a)

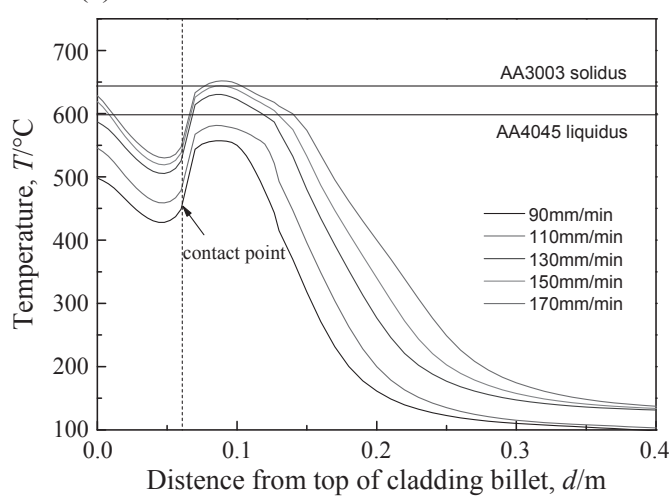

(b)

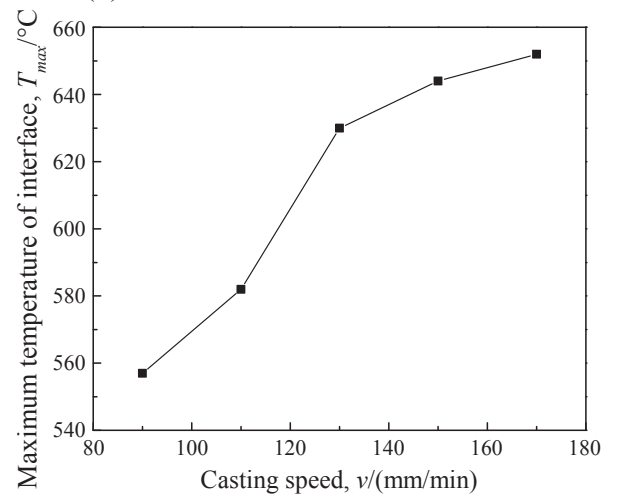

Fig. 5 Cooling curves of composite interface.

(a)

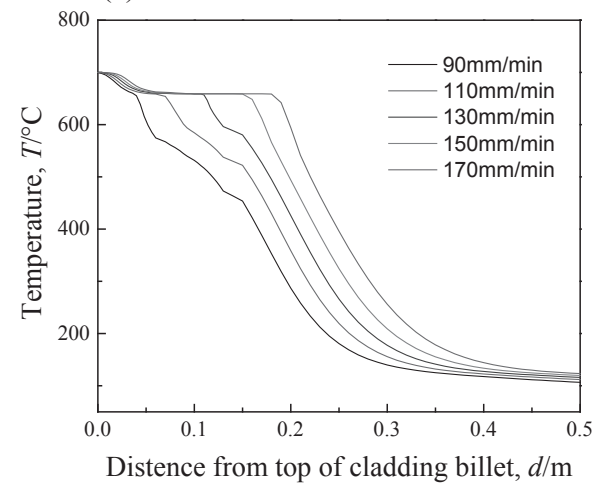

(b)

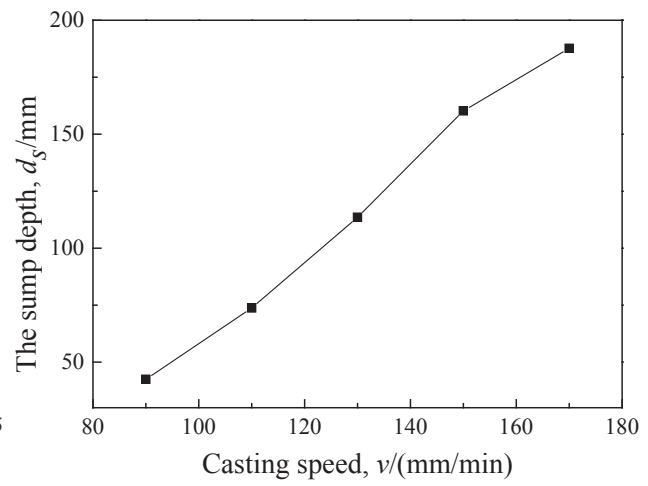

Fig. 6 Cooling curves at the center of cladding billet.

contact temperature), where AA4045 melt just contacted with the supporting layer of AA3003, has a significant increase, as well as the depth of the sump.

In order to investigate the variation of temperature field and obtain a proper casting speed range, the temperature data of composite interface and center zone is extracted and drawn into cooling curves, as shown in Fig. 5 and Fig. 6. With the increasing of casting speed, the staying time of melts in the contact, primary and secondary cooling zones decreases, so that the supporting layer is cladded by AA4045 with a higher temperature. Therefore, the contract temperature increases from $557^{\circ} \mathrm{C}$ to $652^{\circ} \mathrm{C}$, as shown in Fig. 5(b). Similarly, as a result of cooling time shortening, the sump depth elongates from $42 \mathrm{~mm}$ to $188 \mathrm{~mm}$, as shown in Fig. 6(b).

In theory, the lager casting speed, the higher contact temperature, the faster alloy elements diffuse and the higher productivity. However, in the cladding casting process, when the casting speed reaches $170 \mathrm{~mm} / \mathrm{min}$, the contact temperature would reach the AA3003 liquidus $\left(652^{\circ} \mathrm{C}\right)$, and the solidified supporting layer will be remelt badly by AA4045 melt, even mix with it. In addition, a larger sump depth could increase the stress, which maybe produces cracks. ${ }^{22)}$ While the casting speed is down to $90 \mathrm{~mm} / \mathrm{min}$, the contact temperature is just $557^{\circ} \mathrm{C}$, lower than the AA4045 solidus, resulting in that AA4045 starts to solidify before contact with the supporting layer.

Based on the simulation results, the casting speed of AA4045/AA3003 cladding billet with no breaking support- ing layer or discontinuing casting process is predicted at a range from $110 \mathrm{~mm} / \mathrm{min}$ to $150 \mathrm{~mm} / \mathrm{min}$.

\subsection{Experimental results}

As shown in Fig. 7, cladding billets were cast by direct chill semi-continuous process at different casting speed, $90 \mathrm{~mm} / \mathrm{min}, 110 \mathrm{~mm} / \mathrm{min}, 130 \mathrm{~mm} / \mathrm{min}, 150 \mathrm{~mm} / \mathrm{min}$, and $170 \mathrm{~mm} / \mathrm{min}$, respectively. The result shows that when casting speed is equal $90 \mathrm{~mm} / \mathrm{min}$, the AA4045 melt was cooled excessively and could hardly flow freely. As a result, the mold filling was insufficient, AA4045 had already solidified before flowing into outer-graphite and the two alloys were separated from each other, as shown in Fig. 7(a). When casting speed is equal $170 \mathrm{~mm} / \mathrm{min}$, the contact temperature is higher than the AA3003 liquidus. The overheated melt in the center of AA3003 would break through the thinner supporting layer, the solidifying AA4045 flowed out, and the two alloys were mixed, as marked in Fig. 7(e). In the end, cladding casting has to be stopped. Therefore, the cladding billets with an excellent surface quality and well interface were prepared at casting speed of $110 \mathrm{~mm} / \mathrm{min}, 130 \mathrm{~mm} / \mathrm{min}$ and $150 \mathrm{~mm} / \mathrm{min}$, as shown in Fig. 7(b), (c), (d).

During the casting process, the contact temperature should be in range of the AA4045 solidus to the AA3003 liquidus. This ensures that AA4045 could flow freely and would not remelt the supporting layer. With the matching, casting speed should be range of $110 \mathrm{~mm} / \mathrm{min}$ to $150 \mathrm{~mm} / \mathrm{min}$ for 

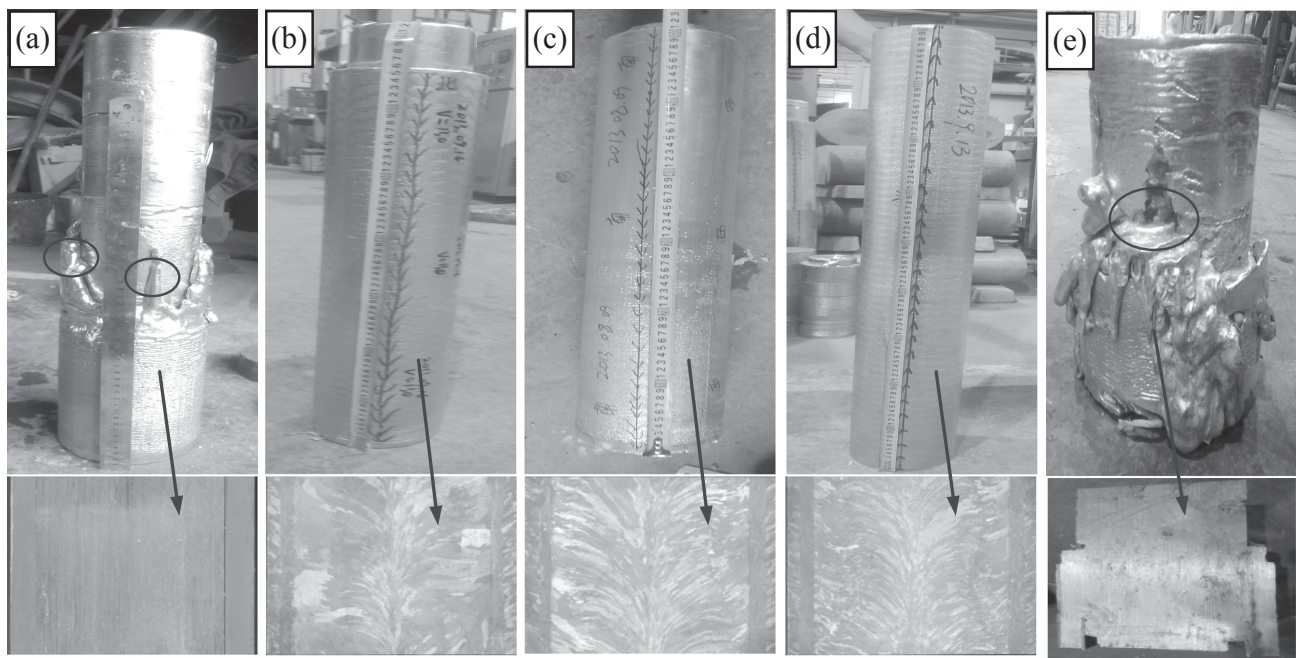

Fig. 7 Photographs of cladding billets cast at the different casting speeds: (a) $v=90 \mathrm{~mm} / \mathrm{min}$; (b) $v=110 \mathrm{~mm} / \mathrm{min}$; (c) $v=130$ $\mathrm{mm} / \mathrm{min}$; (d) $v=150 \mathrm{~mm} / \mathrm{min}$; (e) $v=170 \mathrm{~mm} / \mathrm{min}$.

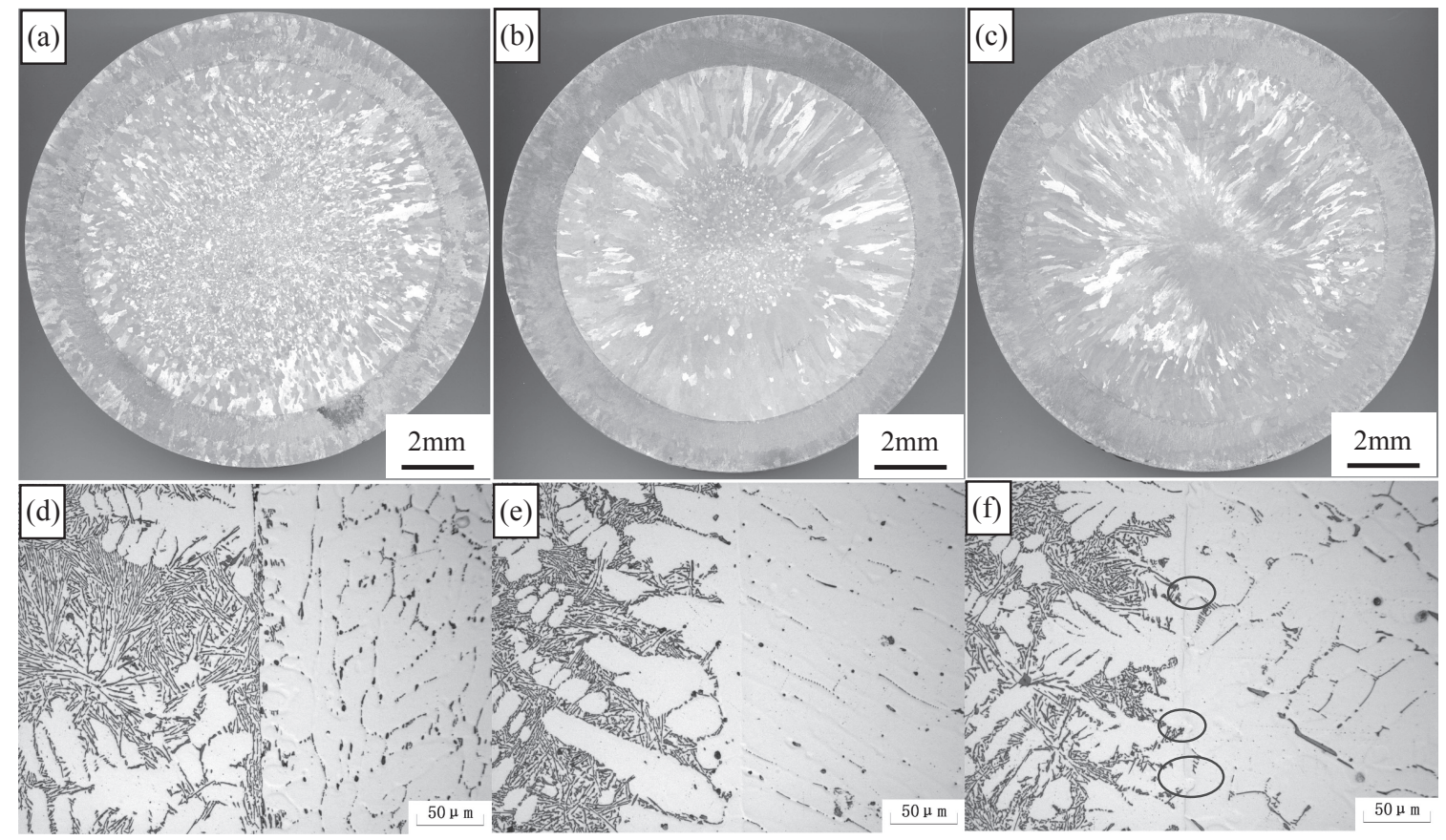

Fig. 8 The macrostructures and microstructures at the interface of the cladding billets in different casting speeds: (a)(d) $v=110 \mathrm{~mm} / \mathrm{min}$; (b)(e) $v=130 \mathrm{~mm} / \mathrm{min}$; (c)(f) $v=150 \mathrm{~mm} / \mathrm{min}$.

AA4045/AA3003 in size of $\Phi 140 \mathrm{~mm} / \Phi 110 \mathrm{~mm}$ cladding casting. The experiment results have a good agreement with the simulation. The simulation result could play a guiding significance role in the the experiments.

\subsection{Microstructure and mechanical properties of clad- ding billets}

The cladding billets were prepared successfully at different casting speed, $110 \mathrm{~mm} / \mathrm{min}, 130 \mathrm{~mm} / \mathrm{min}$ and $150 \mathrm{~mm} / \mathrm{min}$ respectively, using the process parameters obtained from numerical simulation. The macrostructures and microstructures at different casting speed are displayed in Fig. 8. The two alloy layers are revealed by two different contrasts. The interfaces separate the two layers clearly, as shown in Fig. 8(a), (b), (c). After AA3003 was poured into the inner- crystallizer, some equiaxed grains formed on the substrates of heterogeneous nucleation at the core-layer interior. Then, AA3003 continued to solidify along the heat transfer direction, forming the coarse columnar zone. At the center of core-layer, the isotropic heat transfer resulted in forming coarser equiaxed grains. AA4045 flowed into the outercrystallizer and was cooled by outer-crystallizer more intensely and AA3003 solidification shell of less intensely. Therefore, the clad-layer external was composed of fine equiaxed grains, whereas the internal was consisted of coarse columnar crystals.

Casting speed affected the macrostructure obviously. As casting speed increase, on the one hand, the cooling time for AA3003 melt will be shortened, resulting in that the supporting layer contacts with AA4045 at a higher temper- 


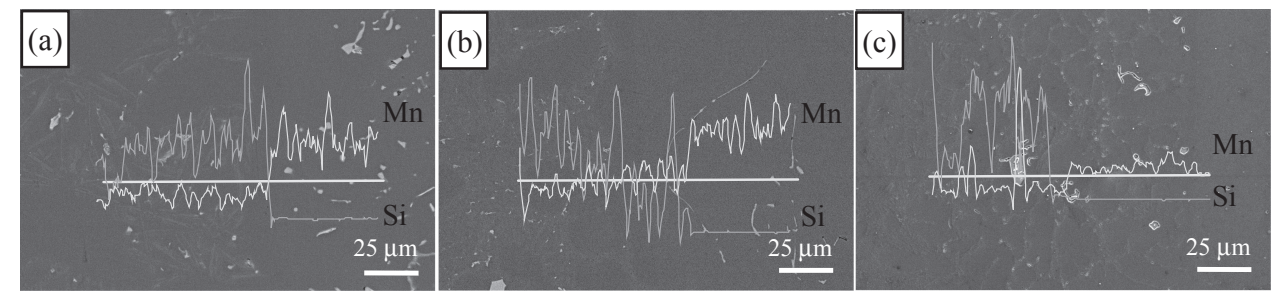

Fig. 9 The EDX analysis results of the cladding billets in different casting speeds: (a) $v=110 \mathrm{~mm} / \mathrm{min}$; (b) $v=130 \mathrm{~mm} / \mathrm{min}$; (c) $v=150 \mathrm{~mm} / \mathrm{min}$.

ature. On the other hand, the temperature gradient in solidifying forefront decreases, lessening the degree of supercooling. A lower degree of supercooling will restrains the nucleation but promotes grains growing. ${ }^{23)}$ For AA3003, the area of columnar structures increased and the grain size enlarged, while the equiaxed zone decreased and the grain size reduced with the increase of casting speed. However, there was little disparity in AA4045.

The micro-interface is shown in Fig. 8(d), (e), (f). It can be seen that acicular eutectic silicon crystals (black part) are distributed at the boundaries of the coarse $\alpha$-Al grains (white part) in AA4045; whereas some phases containing manganese (black parts) are embedded in the $\alpha$-Al matrix (white part) in AA3003. When the casting speed is $110 \mathrm{~mm} / \mathrm{min}$, the contact temperature was only $582^{\circ} \mathrm{C}$ (just above AA4045 solidus, $577^{\circ} \mathrm{C}$ ), reaching eutectic temperature of $\mathrm{Al}-\mathrm{Si}$ and precipitating eutectic directly. Therefore, AA4045 started to solidify before contacted the supporting layer of AA3003. There was no full diffusion during the process of bonding and solidification of the two alloys. With the increasing of casting speed, reaching $130 \mathrm{~mm} / \mathrm{min}$, the contact temperature reached over $630^{\circ} \mathrm{C}$ (higher than $\mathrm{AA} 4045$ solidus, $577^{\circ} \mathrm{C}$, but lower than AA3003 liquidus, $645^{\circ} \mathrm{C}$ ). The primary $\alpha$-Al grains of AA4045 precipitated firstly and grew attaching to the supporting layer. The eutectic silicon precipitated with the reaching eutectic temperature at the interface. However, when casting $150 \mathrm{~mm} / \mathrm{min}$, the contact temperature was $644^{\circ} \mathrm{C}$ (closed to AA3003 liquidus, $645^{\circ} \mathrm{C}$ ), resulting in some excessive re-melting of supporting layer, as shown in Fig. 8(f).

Figure 9 presents the energy dispersive X-ray spectroscope (EDX) linear scan analysis of $\mathrm{Si}$ and $\mathrm{Mn}$ across the composite interface. Clear concentration differences are observed for the two elements. The content of the element Si clearly decreases from AA4045 to AA3003, while the content of the element $\mathrm{Mn}$ increases across the bonding interface. With casting speed increase, the Mn element had lager degree of diffusion so that some phases containing manganese formed when the casting speed reached 150 $\mathrm{mm} / \mathrm{min}$ (as shown in Fig. 8(c)), while the diffusion of $\mathrm{Si}$ element had little variation.

According the Fick's laws of diffusion, if the diffusion process of every element is independent, the diffusion equation can be shown as

$$
\frac{\partial C}{\partial t}=D \frac{\partial^{2} C}{\partial x^{2}}
$$

The diffusion coefficient $D$ can be analyzed by following equation

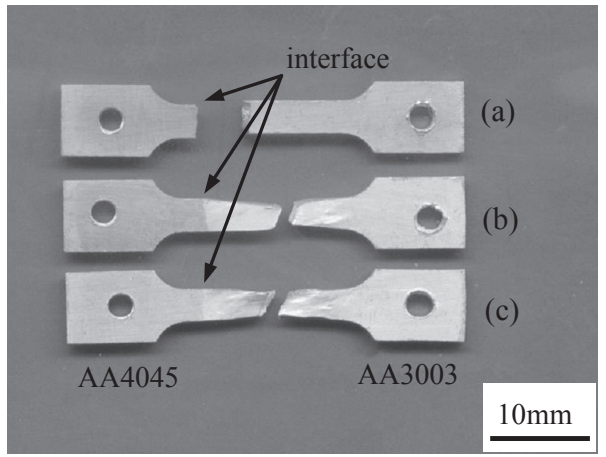

Fig. 10 Specimens of the cladding billets at different casting speeds after tensile tests: (a) $v=110 \mathrm{~mm} / \mathrm{min}$; (b) $v=130 \mathrm{~mm} / \mathrm{min}$; (c) $v=150$ $\mathrm{mm} / \mathrm{min}$.

$$
D=D_{0} \exp \left(-\frac{Q}{R T}\right)
$$

where $D_{0}$ is the diffusion constant, $Q$ is activation energy for diffusion, $R$ is the universal gas constant and $T$ is the absolute temperature.

From the above equations, the temperature played a key role in affecting the diffusion coefficient. As the increase of casting speed, on the one hand, the contact temperature rose up. The alloy elements had lager vibrational energy to get over the barrier by energetic fluctuation and a relatively large diffusion coefficient. On the other hand, the contact time in solid-liquid state decreased, resulting in the diffusion time shortened. However, the former has an exponential effect on the diffusion of alloy elements, but the later has a linear. In addition, the Mn element diffused from solid AA3003 to liquid AA4045, while the $\mathrm{Si}$ element diffused reversely. There is a higher diffusion rate from liquid to solid than that conversely. ${ }^{24)}$ Therefore, the increasing of casting speed, resulting in the contact temperature rising up, further accelerated the diffusion of $\mathrm{Mn}$ atoms than $\mathrm{Si}$ atoms, as shown in Fig. 9(a), (b), (c).

\subsection{Interfacial mechanical properties}

Tensile test is an efficient approach to estimate the interface bonding. Figure 10 shows the fractured tensile samples for different casting speeds. Increasing casting speed led to the site of fracture interface into substrate AA3003. The tensile strength of the composite interface and the substrate AA3003 at different casting speeds are shown in Fig. 11. The casting speed has a greater effect on interface bonding. For sample (a), the fracture occurred at the composite interface with average tensile strength, $64.2 \mathrm{MPa}$, 


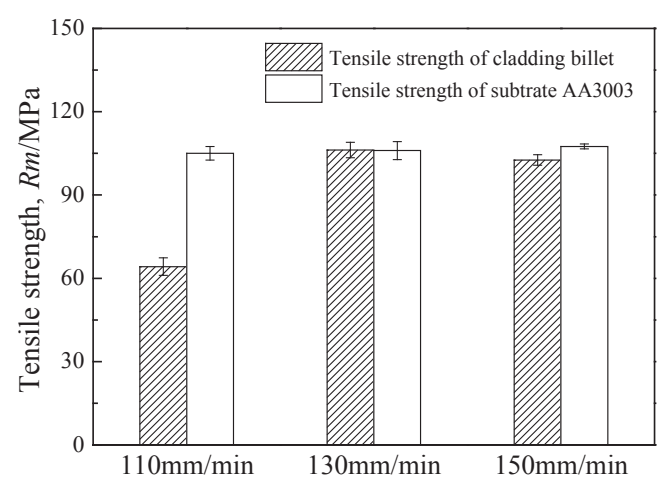

Fig. 11 The tensile strength of the cladding billets and substrate AA3003 at different casting speeds.

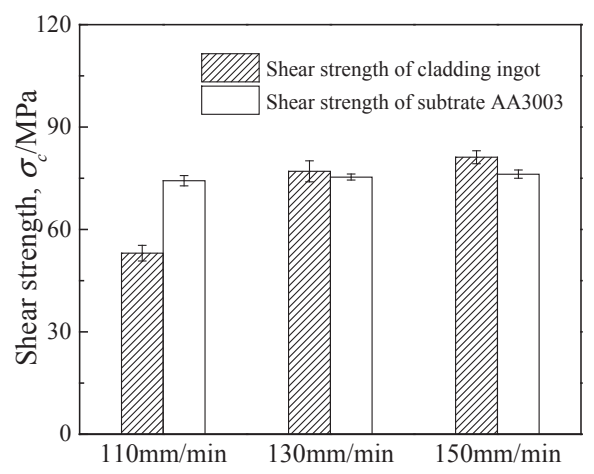

Fig. 12 The shear strength at different casting speeds.

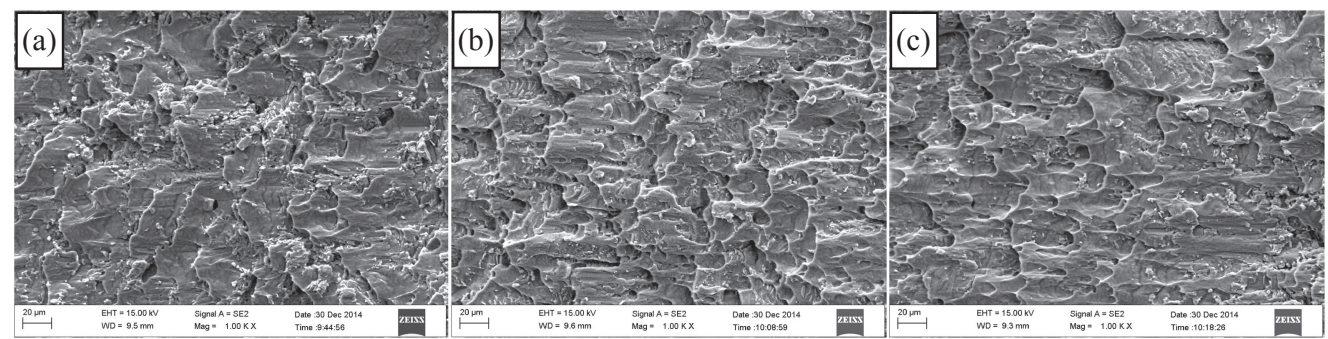

Fig. 13 FESEM micrographs of shear fracture of AA3003 side with different casting speed: (a) $v=110 \mathrm{~mm} / \mathrm{min}$; (b) $v=130 \mathrm{~mm} / \mathrm{min}$; (c) $v=150 \mathrm{~mm} / \mathrm{min}$.

lower than substrate AA3003, $105 \mathrm{MPa}$. At $110 \mathrm{~mm} / \mathrm{min}$, lower contact temperature slowed down the diffusion at the composite interface, corresponding to the EDX analysis result in Fig. 8(a). For sample (b) and sample (c), their tensile strength is near that of substrate AA3003 and the fracture occurred at the AA3003 side, while the interface remains well. Higher contact temperature, which was brought by casting speed increasing, made the alloy elements diffuse adequately. Therefore, when casting speed reach $130 \mathrm{~mm} /$ min or higher within a limited range, the two alloys bonded metallurgical.

Shearing test reflects quantitatively interface bonding strength, rather than tensile test confirming qualitatively that bonding strength is higher than the softer substrate. Meanwhile, shearing strength could provide reliable parameters for subsequent composite pipe extrusion. With reference to the standards by Jing, ${ }^{25,26)}$ shear strength is tested and shown in Fig. 12. The FESEM micrographs of shear fracture of AA3003 side reveal the shear results, as shown in Fig. 13. At $110 \mathrm{~mm} / \mathrm{min}$, the shear strength of composite interface is lower than that of substrate AA3003, and the shear fracture with few dimples reveals that brittle failure occurred at the composite interface (Fig. 13(a)), indicating that the two alloys contacted through little diffusion. Increasing casting speed led to an increase in shear strength due to greater interdiffusion of the alloy elements ( $\mathrm{Si}$ and $\mathrm{Mn}$ ) in both alloys. In contrast, fracture surfaces of composite interface at casting speeds $(130 \mathrm{~mm} / \mathrm{min}$ and $150 \mathrm{~mm} / \mathrm{min})$ show ductile failure such as a number of dimples (Fig. 13(b), (c)). The shear strength of composite interface increased obviously and exceeded substrate AA3003, due to more adequate diffusion with higher casting speed.
Consequently, there is a well agreement among the microstructures, the EDX analysis results and the mechanical properties of composite interface with different casting speed.

\section{Conclusions}

A mathematic model for the coupled of fluid flow, heat transfer and solidification to describe the process of cladding casting was present. The effect of casting speed on temperature field and solidification process was vestigated. The model has been verified by the fabrication of AA4045/ AA3003 cladding billet. It was found that there was a good agreement between the simulation results and experiment and the following conclusions were drawn:

(1) The mathematic model is accurate and credible to describe the process of cladding casting with various technological parameters.

(2) With the increase of casting speed, the contact temperature rises up and the sump depth would be elongated observably. Too low $(90 \mathrm{~mm} / \mathrm{min})$ and too high $(170 \mathrm{~mm} / \mathrm{min})$ casting speed would lead to the failure of the cladding casting, because of early solidification of AA4045 and melting through the supporting layer, respectively.

(3) The increasing of casting speed, resulting in the contact temperature rising up, further accelerated the diffusion of $\mathrm{Mn}$ atoms than $\mathrm{Si}$ atoms. It is practical to prepare AA4045/AA3003 cladding billet in size of $\Phi 140 \mathrm{~mm} /$ $\Phi 110 \mathrm{~mm}$ by direct chill semi-continuous casting process with casting speed ranging from $130 \mathrm{~mm} / \mathrm{min}$ to $150 \mathrm{~mm} / \mathrm{min}$.

(4) Increasing of casting speed intensifies the interdiffusion 
of alloy elements. When casting speed reaches or greater than $130 \mathrm{~mm} / \mathrm{min}$, the diffusion of alloy elements is enhanced markedly. Correspondingly, the interfacial strength exceeds substrate AA3003, $106 \mathrm{MPa}$ in tensile test and $77 \mathrm{MPa}$ of shear strength, respectively. It means that the two alloys achieved a well metallurgical bonding.

\section{Acknowledgments}

The authors gratefully acknowledge the supports of the National Basic Research Program of China (Grant number 2012CB723307-03), the National Science Foundation for the Youth (Grant number 51204046) and the doctoral foundation of China Ministry of Education (Grant number 20130042130001).

\section{REFERENCES}

1) W. S. Miller, L. Zhuang, J. Bottema, A. J. Wittebrood, P. D. Smet, A. Haszler and A. Vieregge: Mater. Sci. Eng. A 280 (2000) 37-49.

2) K. J. M. Papis, B. Hallstedt, J. F. Loffler and P. J. Uggowiter: Acta Mater. 56 (2008) 3036-3043.

3) I. K. Kim and S. I. Hong: Mater. Des. 49 (2013) 935-944.

4) T. Liu, Q. D. Wang, Y. D. Sui, Q. G. Wang and W. J. Ding: Mater. Des. 68 (2015) 8-17.

5) Y. Liu and Z. T. Wang: Light Alloy Fabricat. Technol. 39 (2011) 1-16.

6) M. Talebian and M. Alizadeh: Mater. Sci. Eng. A 590 (2014) 186-193.

7) M. Z. Quadir, M. Ferry, O. Al-Buhamad and P. R. Munroe: Acta. Mater. 57 (2009) 29-40.

8) S. Niknejad, L. Liu, M. Y. Lee, S. Esmaeili and N. Y. Zhou: Mater. Sci.
Eng. A 618 (2014) 323-334.

9) M. Asemabadi, M. Sedighi and M. Honarpisheh: Mater. Sci. Eng. A 558 (2012) 144-149.

10) J. Zhang, G. Q. Luo, Y. Y. Wang, Q. Shen and L. M. Zhang: Mater. Lett. 83 (2012) 189-191.

11) C. G. Kang, Y. J. Jung and H. C. Kwon: J. Mater. Process. Technol. 124 (2002) 49-56.

12) K. Y. Rhee, W. Y. Han, H. J. Park and S. S. Kim: Mater. Sci. Eng. A 384 (2004) 70-76.

13) Q. Tang, H. F. Ning, D. F. Fu, W. J. Xia, Z. H. Chen and H. L. Ning: Powder Metall. Technol. 22 (2004) 12-15.

14) J. C. Bendyk: Light Metal Age 8 (2006) 48-50.

15) E. I. Marukovich, A. M. Branovitsky, Y. S. Na, J. H. Lee and K. Y. Choi: Mater. Des. 27 (2006) 1016-1026.

16) A. R. Baserinia, H. Ng, D. C. Weckman, M. A. Wells, S. Barker and M. Gallerneault: Metall. Mater. Trans. B 43 (2012) 887-901.

17) Y. Fu, J. C. Jie, L. Wu, J. Park, J. B. Sun, J. Kim and T. J. Li: Mater. Sci. Eng. A 561 (2013) 239-244.

18) W. P. Gan and J. H. Wei: Nonferrous Metals 8 (1998) 206-209.

19) H. T. Zhang, H. Nagaumi, Y. B. Zuo and J. Z. Cui: Mater. Sci. Eng. A 448 (2007) 189-203.

20) X. Han, B. Shao, H. T. Zhang and J. Z. Cui: J. Northeastern Univ. (Natural Science) 35 (2014) 969-973.

21) D. M. Turriff, S. F. Corbin and M. Kozdras: Acta Mater. 58 (2010) 1332-1341.

22) Y. B. Zuo, J. Z. Cui, Z. H. Zhao, H. T. Zhang and K. Qin: Mater. Sci. Eng. A 406 (2005) 286-292.

23) A. E. Ares and C. E. Schvezov: Metall. Mater. Trans. A 38 (2007) 1485-1499.

24) W. Yao, A. P. Wu, G. S. Zou and J. L. Ren: Rare Metal Mater. Eng. 36 (2007) 700-704.

25) Y. A. Jing, Y. Qin, X. M. Zang, Q. Y. Shang and H. Song: J. Alloy. Compd. 617 (2014) 688-698.

26) Y. A. Jing, Y. Qin, X. M. Zang and Y. H. Li: J. Mater. Process. Technol. 214 (2014) 1686-1695. 